\title{
Vitamin K status in peritoneally dialyzed patients with chronic kidney disease
}

\author{
Hanna Stankowiak-Kulpa1, Patrycja Krzyżanowska 2, Lidia Kozioł ${ }^{3}$, Marian Grzymisławski1, \\ Maria Wanic-Kossowska ${ }^{3}$, Jerzy Moczko ${ }^{4}$ and Jarosław Walkowiak ${ }^{2 凶}$
}

'Department of Internal Medicine, Metabolism and Dietetics, Poznań University of Medical Sciences, Poznań, Poland; 2Department of Pediatric Gastroenterology and Metabolism, Poznań University of Medcial Sciences, Poznań, Poland; 3 Department of Nephrology and Transplantology, Poznań University of Medical Sciences, Poznań, Poland; “Department of Computer Science and Statistics, Poznań University of Medical Sciences, Poznań, Poland

\begin{abstract}
Abnormal vitamin $\mathrm{K}$ status was documented in patients with chronic kidney diseases (CKD), especially those undergoing hemodialysis. The data related to patients undergoing peritoneal dialysis (PD) are contradictory. Therefore, in the present study we aimed to evaluate vitamin $\mathrm{K}$ status in patients with CKD who are treated with continuous ambulatory PD. Twenty-eight patients entered into the study. Dialysis vintage ranged from 3 to 89 months. Vitamin $\mathrm{K}$ status was assessed in all subjects using undercarboxylated prothrombin measurement (PIVKA-II). In addition, total protein and albumin levels, total cholesterol, LDL cholesterol, triglyceride, calcium, urea and creatinine concentrations were determined. PIVKA-II concentrations were abnormal in 13 $(46.4 \%)$ subjects. BMI values, both total and LDL cholesterol concentrations were significantly higher in patients with than those without vitamin K deficiency. Moreover, PIVKA II levels correlated with BMI values $(r=0.441$, $p<0.019)$, LDL cholesterol $(r=0.434, p<0.021)$ and creatinine $(r=0.406, p<0.032)$ concentrations. However, through the use of logistic regression analysis and multiple regression analysis, no clinical factor was documented to be the independent risk factor of vitamin $\mathrm{K}$ deficiency. In conclusion, vitamin K deficiency is a frequent condition in peritoneally dialyzed patients. Assessment of vitamin $\mathrm{K}$ status should become a standard procedure in this group of patients.
\end{abstract}

Keywords: vitamin K, kidney disease, dialysis

Received: 29 July, 2011; revised: 17 November, 2011; accepted: 16 December, 2011; available on-line: 20 December, 2011

\section{INTRODUCTION}

The term vitamin $\mathrm{K}$ denotes a family of fat soluble vitamins responsible for post-translational protein modification (Krueger et al., 2009). Vitamin $\mathrm{K}$ is the cofactor of $\gamma$-glutamyl carboxylation of proteins by the microsomal enzyme $\gamma$-glutamyl carboxylase. This post-translational reaction is necessary for the conversion of coagulation factors II, VII, IX, $\mathrm{X}$ and proteins $\mathrm{C}$ and $\mathrm{S}$ into their bioactive forms in the liver (vitamin $\mathrm{K} 1$ and $\mathrm{K} 2$ ). Vitamin K2 is required for $\gamma$-glutamyl carboxylation of osteocalcin, which is secreted by osteoblasts and odontoblasts and of Matrix-Gla Protein (MGP), an inhibitor of vascular medial-calcification that occurs in many different tissues (Małyszko et al., 2002; Małyszko et al., 2004; Holden et al., 2008). It is well known that the tunica media is the major site of MGP expression, yet it still remains unclear by what mechanism MGP prevents arterial calcification. In the general population, vitamin $\mathrm{K}$ supplementation can be used as a preventive measure against vascular calcification and the formation of bioactive coagulation factors (Danziger, 2008).

It is important to establish vitamin $\mathrm{K}$ status in chronic renal failure patients to prevent its potential deficiency and complications that may be related to it, such as bleeding and an increased risk of cardiovascular disease. Subclinical vitamin $\mathrm{K}$ deficiency may not cause any noticeable changes in the levels of coagulation factors, and its detection threshold is very different from that of apparent vitamin $\mathrm{K}$ deficiency. The current European guidelines related to nutrition suggest that vitamin $\mathrm{K}$ deficiency is not found except for cases of prolonged antibiotic therapy and coagulation abnormalities (Fouque et al., 2007). However, abnormal vitamin $\mathrm{K}$ status was documented in patients with chronic kidney diseases (CKD), especially in those subjects undergoing hemodialysis (Pilkey et al., 2007). The data related to patients on peritoneal dialysis (PD) are contradictory (Nagasawa et al., 1998b; Vychytil \& Druml, 1998). Therefore, in the present study, we aimed to evaluate vitamin $\mathrm{K}$ status in patients with CKD who are treated with continuous ambulatory PD.

\section{MATERIALS AND METHODS}

Twenty-eight patients (16 females and 12 males) aged from 27 to 76 years (median $\left[1^{\text {st }}-3^{\text {rd }}\right.$ quartile]: 60 [4868]) with CKD agreed to participate in the study. CKD was of different etiology: 11 patients developed diabetic nephropathy, 11 patients had hypertension related nephropathy, 2 patients had nephropathy of unclear etiology, the rest of the patients developed CKD due to glomerulonephritis, bilateral kidney stone disease, SLE or ischemia. All patients were treated with continuous ambulatory $\mathrm{PD}$ due to $\mathrm{CKD}$. Dialysis vintage ranged from 3 to 89 months (24 [7-37]). None of the patients was anticoagulated with coumarin or warfarin. One patient was treated with low-molecular heparin due to dilated cardiomyopathy secondary to hypertension.

Vitamin $\mathrm{K}$ status was assessed in all subjects using undercarboxylated prothrombin measurements (pro-

e-mail: jarwalk@ump.edu.pl

Abbreviations: CKD, chronic kidney disease; MGP, Matrix-Gla protein; PD, peritoneal dialysis; PIVKA-II, undercarboxylated prothrombin. 
thrombin induced by vitamin $\mathrm{K}$ absence, PIVKA-II) by an enzyme immunoassy method (Asserachrom PIVKAII, Roche Diagnostic, Poland) as described earlier (Acta Alimentaria). The cut-off value was set at $<2 \mathrm{ng} / \mathrm{ml}$. Higher values were considered to be indicative of vitamin $\mathrm{K}$ deficiency. In addition, total protein and albumin levels, total cholesterol, LDL cholesterol, triglyceride, calcium, urea and creatinine concentrations as well as GFR were determined.

The statistical differences in clinical parameters between patients with and without vitamin $K$ deficiency were calculated with the use of the Mann-Whitney test. The relationship between single or all clinical parameters and PIVKA II concentrations were assessed using Spearman correlation and multiple regression analysis, respectively. The influence of clinical parameters on the presence/absence of vitamin $\mathrm{K}$ deficiency was determined with the use of logistic regression analysis.

Mathematical analysis of the collected experimental data was also performed using two data mining procedures to define the potential predictor of vitamin $\mathrm{K}$ deficiency. In the first step, the standard model of classification and regression trees (CR\&'T) was used with the following options: equal misclassification costs, Gini measure of the goodness of fit, estimated prior probabilities, stopping rule - prune on misclassification error (stopping parameter - minimum 5 cases), and tenfold cross validation. Because the splitting value of LDL predictor in the optimal tree (in a generated sequence of four trees) was equal to 100.75 , we tried to change the value to exactly 100 . That trial was made using the interactive trees procedure. Adoption of this corrected level did not change the structure of the misclassification matrix. The distribution of vitamin $\mathrm{K}$ deficiency in patients with LDL concentrations $>100 \mathrm{mg} / \mathrm{dL}$ and in those with low LDL levels was assessed with the use of Chi² test (with Yates correction).

All calculations were performed using STATISTICA (data analysis software system), version 8.0. StatSoft, Inc. (2008).

If not stated otherwise, measures of location are reported as medians $\left[1^{\text {st }}-3^{\text {rd }}\right.$ quartiles]. The level of significance was set at $p<0.05$.

The protocol of the investigation was approved by the Bioethical Committee of the Poznań University of Medical Sciences, Poland. An informed and written consent was obtained from each of the patients.

\section{RESULTS}

PIVKA II concentrations were lower than $2 \mathrm{ng} / \mathrm{mL}$ in $15(53.6 \%)$ patients. In the remaining $13(46.4 \%)$ subjects the concentrations were abnormal, which is indicative of vitamin $\mathrm{K}$ deficiency. Undercarboxylated prothrombin concentrations in this subgroup of patients ranged from 2.2 to $34.8 \mathrm{ng} / \mathrm{mL}\left(4.2\left[1^{\text {st }}-3^{\text {rd }}\right.\right.$ quartiles $]<3.1-7.3>$ ). However, coagulological parameters (prothrombin time, INR) were normal in all subjects studied.

BMI values, LDL and total cholesterol concentrations were significantly higher in patients with vitamin $\mathrm{K}$ deficiency than in those without (Table 1). PIVKA II levels correlated to BMI values $(r=0.441, p<0.019)$, LDL cholesterol $(\mathrm{r}=0.434, p<0.021)$ and creatinine $(\mathrm{r}=0.406$, $p<0.032$ ) concentrations. No other significant correlations were stated. However, using logistic regression analysis and multiple regression analysis, no clinical fac- tor was documented to be the independent risk factor of vitamin $\mathrm{K}$ deficiency.

Vitamin $\mathrm{K}$ deficiency was significantly more frequent in patients with higher LDL concentrations than in those with lower LDL levels $(p<0.0018)$. The sensitivity and negative predictive value of such classification in the differentiation between selected groups was very high ( $92.3 \%$ and $91.7 \%$, respectively), with a moderate specificity and positive predictive value $(73.3 \%$ and $75.0 \%$, respectively).

\section{DISCUSSION}

Our results suggest that peritoneally dialyzed patients with $\mathrm{CKD}$ are at high risk of subclinical vitamin $\mathrm{K}$ deficiency as defined by the specific and sensitive marker, PIVKA-II. In the first reports on vitamin $\mathrm{K}$ status in $\mathrm{CKD}$, it was documented that phylloquinone concentrations in hemodialyzed and peritoneally dialyzed patients, kidney transplant recipients, chronic renal failure patients and healthy subjects did not differ (Małyszko et al., 2002; Małyszko et al., 2004) or that phylloquinone levels in PD patients could be even higher than in healthy controls (Vychytil \& Druml, 1998). However, in subsequent studies, frequent vitamin $\mathrm{K}$ deficiency was reported in hemodialyzed patients and those not requiring renal replacement therapy (Pilkey et al., 2007; Nerlander et al., 2009; Holden et al., 2010; Schlieper et al., 2011). Pilkey et al. (2007) revealed abnormal phylloquinone and undercarboxylated osteocalcin concentrations in $29 \%$ and $93 \%$ of the hemodialyzed subjects, respectively. Subclinical vitamin $\mathrm{K}$ deficiency criteria based upon phylloquinone, undercarboxylated osteocalcin and PIVKA II levels were met respectively by $6 \%, 60 \%$ and $97 \%$ of the patients not requiring renal replacement therapy (Holden et al., 2010). Schlieper et al. (2011) documented abnormal PIVKA II concentrations in $64 \%$ of the hemodialyzed subjects. On the other hand, Nerlander et al. (2009) found vitamin $\mathrm{K}$ deficiency based upon PIVKA II measurements in $14.6 \%$ of patients. However, $60 \%$ of them were warfarinized. The obtained data are important, particularly for patients with CKD and subclinical vitamin $\mathrm{K}$ deficiency who require treatment with warfarin or coumarins. These patients could have increased risk of bleeding and disturbed bone mineralization secondary to this treatment.

The data obtained in patients undergoing PD are less concordant (Nagasawa et al., 1998b; Vychytil \& Druml, 1998; Małyszko et al., 2002; Małyszko et al., 2004; Holden et al., 2008). Vychytil \& Druml (1998) documented that the mean vitamin $K$ concentrations in their patients treated with PD were twice as high as those in healthy controls. In two other reports (Małyszko et al., 2002; Małyszko et al., 2004) phylloquinone concentrations in PD patients and healthy subjects did not differ. However, Holden et al. (2008) documented frequent vitamin K deficiency; abnormal phylloquinone levels were present in $23.8 \%$ of patients, with high percentages (>20\%) of undercarboxylated osteocalcin present in all subjects studied. Our results are in favor of the opinion that vitamin $\mathrm{K}$ deficiency is frequent in PD patients. Possible reasons for the contradictory results might be related to different methods assessing vitamin $\mathrm{K}$ status. One available procedure is to measure vitamin $\mathrm{K} 1$ and $\mathrm{K} 2$ concentrations (ie. phylloquinone and menaquinone) levels. On the other hand, it is possible to assess the presence of undercarboxylated proteins (prothrombin and os- 
Table 1. Basic clinical features in patients with and without vitamin K deficiency.

\begin{tabular}{|c|c|c|c|}
\hline \multirow[t]{2}{*}{ Variables } & \multicolumn{2}{|c|}{$\begin{array}{l}\text { Vitamin K deficiency } \\
\text { Median [ } 1^{\text {st}} 3^{\text {rd }} \text { quartiles] }\end{array}$} & \multirow[t]{2}{*}{ Statistical significance } \\
\hline & No & Yes & \\
\hline Age (years) & $57[40.5-73.5]$ & $60[57-66]$ & 0.29 \\
\hline BMI $\left(\mathrm{kg} / \mathrm{m}^{2}\right)$ & $23.6[22.3-28.6]$ & $31.8[29.9-38.4]$ & 0.0018 \\
\hline Dialysis vintage (months) & 20 [8-37] & $27[7-35]$ & 0.96 \\
\hline eGFR (ml/min) & $12[8.5-13.5]$ & 9 [7-11] & 0.13 \\
\hline Total protein (g/dL) & $6.5[6.1-6.8]$ & $7.0[6.6-7.3]$ & 0.12 \\
\hline Albumin (g/dL) & $4.00[3.60-4.35]$ & $3.80[3.39-4.30]$ & 0.62 \\
\hline Calcium (mg/dL) & $9.55[8.73-9.85]$ & $8.75[8.45-9.58]$ & 0.37 \\
\hline Urea (mg/dL) & 112 [78-135] & 114 [99-127] & 0.65 \\
\hline Creatinine (mg/dL) & $5.94[4.97-7.85]$ & 8.07 [6.71-9.83] & 0.07 \\
\hline Cholesterol (mg/dL) & 177.0 [159.5-197.0] & 208 [188-249] & 0.037 \\
\hline LDL cholesterol (mg/dL) & $95.6[81.5-106.3]$ & $125.3[105.3-169.1]$ & 0.006 \\
\hline Triglycerides (mg/dL) & 101 [82-130.5] & 167 [89-273] & 0.11 \\
\hline
\end{tabular}

teocalcin). The other possible explanation is the lack of well-defined and reliable control groups which may result in misleading interpretation of the collected data.

Patients with inadequate vitamin $\mathrm{K}$ status seem to have a higher rate of cardiovascular and cerebrovascular diseases due to increased risk of vascular tunica media calcification (Nagasawa et al., 1998a; Krueger et al., 2009). The role of vitamin K-dependent proteins as well as the exact mechanisms of their action are not fully understood. Therefore, further studies should be carried out on larger groups of patients with CKD to elucidate this issue. Vitamin K2 supplementation may be a viable pharmacological treatment option for CKD patients with vitamin $\mathrm{K}$ deficiency (Schlieper et al., 2011). The optimal indicated dosage of such supplementation should be further explored as well as the safety of that treatment in patients on long-term warfarin or coumarin therapy (Fusaro et al., 2011).

Although PIVKA II concentrations in the present study were found to be somehow related to nutritional status, renal function, and cholesterol concentrations, we did not identify any independent risk factor for vitamin $\mathrm{K}$ deficiency. However, we did not include vitamin $\mathrm{K}$ intake within the model, which is an important drawback of the analysis. The small number of patients included is another limitation of the study which results in its limited power. Although it was proven through mathematical analysis that LDL cholesterol could potentially serve as a potential predictor in optimal tree decision, further studies are needed to validate this finding. Vitamin $\mathrm{K}$ deficit seems to be rather unlikely in patients with low LDL concentrations (high negative predictive value). Interestingly, Vychytil \& Druml (1998) and Nagasawa et al. (1998a) documented significant correlations between phylloquinone concentrations and total cholesterol levels which were not observed in our study. However, they assessed vitamin $K$ levels, whereas we searched for the presence of undercarboxylated prothrombin representing vitamin $\mathrm{K}$ deficiency. The observed discrepancies might also potentially be related to different nutritional behaviors. However, the small sample size of the studies should be kept in mind.

In other multiple linear regression models with logged values of various measurements of vitamin $K$ status (phylloquinone, undercarboxylated osteocalcin, PIVKA
II) it was documented that the potential significant predictors include: dietary vitamin $\mathrm{K}$, triglycerides, ApoE4 allele, dialysis vintage, levels of phosphates and calcium (Pilkey et al., 2007; Holden et al., 2010). However, the observed effects were minor and different predictors were significant in different models. Moreover, the analysis was conducted in patients not requiring renal replacement therapy (Holden et al., 2010) or in hemodialyzed subjects (Pilkey et al., 2007). Taking into account the frequency of vitamin $\mathrm{K}$ deficiency reported in the present study as well as in other publications, the assessment of vitamin $\mathrm{K}$ status should become a standard procedure in PD patients and probably in all CKD subjects.

The measurement of PIVKA II concentrations is done with the use of the enzyme immunoassay method (ELISA) whereas vitamin K1 levels are determined using HPLC. Since the availability of ELISA is definitely far more common therefore, at present, we suggest the assessment of PIVKA II. Vitamin K status should be checked as an annual routine control. In case of vitamin $\mathrm{K}$ deficiency, the supplementation should be introduced and adjusted in three-month intervals. In the meantime, the significance of vitamin K2 status and supplementation should be elucidated which may potentially imply the change of recommendations. It is especially important since vitamin $\mathrm{K} 2$ has a higher affinity for $\gamma$-glutamyl carboxylase and has a more widespread tissue distribution (Krueger 2009).

In conclusion, vitamin $\mathrm{K}$ deficiency is a frequent condition in peritoneally dialyzed patients. Assessment of vitamin $\mathrm{K}$ status should become the standard procedure in this group of patients.

\section{REFERENCES}

Danziger J (2008) Vitamin K-dependent proteins, warfarin, and vascular calcification. Clin I Am Soc Nephrol 3: 1504-1510.

Fouque D, Vennegoor M, ter Wee P, Wanner C, Basci A, Canaud B, Haage P, Konner K, Kooman J, Martin-Malo A, Pedrini L, Pizzarelli F, Tattersall J, Tordoir J, Vanholder R (2007) EBPG guideline on nutrition. Nephrol Dial Transplant. 22 Suppl 2:ii45-ii87.

Fusaro M, Crepaldi G, Maggi S, Galli F, D’Angelo A, Calò L, Giannini S, Miozzo D, Gallieni M (2011) Vitamin K, bone fractures, and vascular calcifications in chronic kidney disease: an important but poorly studied relationship. J Endocrinol Invest 34: 317-323.

Holden R, Iliescu E, Morton AR, Booth SL (2008) Vitamin K status of Canadian peritoneal dialysis patients. Perit Dial Int 28: 415-418. 
Holden RM, Morton AR, Garland JS, Pavlov A, Day AG, Booth SL (2010) Vitamins K and D status in stages 3-5 chronic kidney disease. Clin J Am Soc Nephrol 5: 590-597.

Krueger T, Westenfeld R, Ketteler M, Schurgers LJ, Floege J (2009) Vitamin $\mathrm{K}$ deficiency in CKD patients: a modifiable risk factor for vascular calcification? Kidney Int 76: 18-22.

Małyszko J, Wołczyński S, Skrzydlewska E, Małyszko JS, Myśliwiec M (2002) Vitamin K status in relation to bone metabolizm in patients with renal failure. Am J Nephrol 22: 504-508.

Małyszko JS, Małyszko J, Skrzydlewska E, Pawlak K, Myśliwiec M (2004) Protein Z and witamin K in kidney disease. Rocz Akad Med Bialymst 49: 197-200.

Nagasawa Y, Fujii M, Kajimoto Y, Imai E, Hori M (1998a) Vitamin $\mathrm{K} 2$ and serum cholesterol in patients on continuous ambulatory dialysis. The Lancet 351: 724.

Nagasawa Y, Fujii M, Kajimoto Y, Imai E, Hori M (1998b) bis Vitamin $\mathrm{K}$ supplementation in patients on continuous ambulatory peritoneal dialysis. The Lancet 352: 1735. Authors reply.
Nerlander M, Voong K, Manghat P, Hampson G, Harrington D, Shearer M, Goldsmith D (2009) Subclinical deficiency of vitamin K status in chronic kidney disease. World Congress of Nephrology Poster session), Milan, May 22-26.

Pilkey RM, Morton AR, Boffa MB, Noordhof C, Day AG, Su Y, Miller LM, Koschinsky ML, Booth SL (2007) Subclinical vitamin K deficiency in hemodialysis patients. Am J Kidney Dis 49: 432-439.

Schlieper G, Westenfeld R, Krüger T, Cranenburg EC, Magdeleyns EJ, Brandenburg VM, Djuric Z, Damjanovic T, Ketteler M, Vermeer C, Dimkovic N, Floege J, Schurgers L (2011) Circulating nonphoshorylated carboxylated matrix Gla protein predicts survival in ESRD. $J$ Am Soc Nephrol 22: 387-395.

Vychytil A, Druml W (1998) Vitamin K supplementation in patients on continuous ambulatory peritoneal dialysis. The Lancet 351: 1734 1735 . 